\title{
DO DOUBLE TAX TREATIES PROMOTE ECONOMIC GROWTH? EVIDENCE FROM AFRICA
}

Hema Soondram, University of Mauritius, Reduit, Mauritius Martin Samy, Universite des Mascareignes, Rose Hill, Mauritius

Bhavish Jugurnath, University of Mauritius, Reduit, Mauritius

$$
\text { dx.doi.org/10.18374/JIFE-20-3.2 }
$$

\begin{abstract}
This study is the first to examine the effects of double tax treaties (DTTs) on economic growth in Africa. The Generalised Method of Moments (GMM) results show that DTTs are significantly related to economic growth. The presence of double tax treaties in these countries brings about positive and increased growth. The findings suggest that African governments which wish to promote growth and FDI should sign more DTTs in spite of recent criticisms on how tax treaties are not beneficial to developing countries.
\end{abstract}

Keywords: Economic Growth, Double Tax Treaties, Africa 